\title{
Using Mathematical Modeling as an Example of Qualitative Reasoning in Metaphysics. A Note on a Defense of the Theory of Ideas
}

\author{
Bartłomiej Skowron \\ International Center for Formal Ontology \\ Department of Administration and Social Sciences, Warsaw University of Technology \\ ul. Plac Politechniki 1, 00-661 Warszawa, Poland \\ Pontifical University of John Paul II in Cracow \\ Email: bartlomiej.skowron@gmail.com \\ http://www.math.uni.wroc.pl/ s 160571/nowa.html
}

\begin{abstract}
This is an outline of a defense of the theory of Ideas. I propose-using qualitative reasoning in metaphysics-the new incarnation of the theory of Ideas and I try to defend the theory against traditional counterarguments. The starting point are the theories of Ideas of Plato and Ingarden and an ontology of Ideas proposed by Kaczmarek; these theories are paraphrased-using a modified method of semantic paraphrases of Ajdukiewiczand presented in terms of the basic concepts of category theory. To paraphrase Ideas as categories I propose recognized category theory as a pattern for the theory of Ideas. This recognitionbased on an analogy between mathematical structures and philosophical structures-is the core of the qualitative reasoning in metaphysics. It could also be called a mathematical philosophy or mathematical modeling in metaphysics. I invoke an arrows-like, i.e. no-object-oriented, formulation of a category and I base the proposed theory of Ideas on that formulation. The components of an Idea are arrows and their compositions (equivalents of changes and transformations); objects in this approach are special arrows namely the identity arrows. Using the category of higher dimensions I introduce the concept of the dimension of an Idea (and other concepts) which allows me to refute the argument of the "third man".
\end{abstract}

\section{BACKGROUND}

$\mathbf{P}$ LATO divided reality into what really exists (Forms or Ideas) and everything else. The first is not easily perceptible, the second is indeed perceptible and tangible, but essentially it is not real-it just reflects the first. Plato's Ideas were a perfect and ideal realm, they were eternal and changeless. Things that appear to our senses only participate in the Ideas, imitate them; Ideas are models for things that are present in things. The realm of things is variable and unstable, they arise and perish, Ideas are timeless, constant, stable, independent and original. One can only learn about them intellectually. It is beyond a doubt that the Platonic bifurcation of reality is of fundamental importance to Western thought. According to A. N. Whitehead: "The safest general characterization of the European philosophical tradition is that it consists of a series of footnotes to Plato" (Whitehead, 1929, p. 39).
Aristotle pointed out many difficulties in Plato's theory of Ideas, including the one that there are Ideas of negation (Negation Argument), but there should not be; he pointed to the argument of the "third man". As he claimed: "[T]o say that they are patterns and the other things share in them is to use empty words and poetical metaphors" (Met. I, 997b 5-12). He also complained of his contemporaries that mathematics "has come to be identical with philosophy". Next Aristotle inquired as to how many Ideas can arise from one (One-Many Argument), as is the case with numbers. With dissatisfaction and disbelief he accepted the fact that Ideas can be patterns not only for things, but also for other Ideas (Pattern Argument).

\section{A. Prior Contemporary Research on Ideas}

Philosophy of the twentieth century, especially phenomenology and analytic philosophy, has undertaken the task of creating new theories of Ideas. Some of the works of Roman Ingarden (Ingarden, 1925) and Jean Héring (Héring, 1921) on the one hand, and Kit Fine (Fine, 1995), Edward Zalta (Zalta, 1983) and Janusz Kaczmarek (Kaczmarek, 2008) on the other hand were devoted, in a certain way, to Ideas.

Ingarden and Kaczmarek's study of the Ideas most influenced a formulation of the proposed dynamic and structural theory of Ideas. Ingarden in his Essentiale Fragen partially modifying the account of Plato and partially rejecting it, presented a full-fledged theory of Ideas. Ingarden captured the formal two-sidedness of Ideas and introduced constants and variables in the content of Ideas. He examined and analyzed the ontological source of the content of Ideas, that is to say the pure ideal qualities. In Kaczmarek's account the ideal objects were represented by a pair of functions. From the point of view of the theory of Ideas presented in this note the crucial point of Kaczmarek's formalized ontology is that the objects were represented by functions, not by elements or ingredients. The "material" of ideal objects were functions.

A further stimulus of the proposed theory was Thomas Mormann Theory of Object. Mormann (Mormann, 1997) inspired by David Armstrong (Armstrong, 1989) and Brian 
Skyrms (Skyrms, 1993)—presented an ontology of objects as functions. More specifically he has created a combinatorial theory of possible worlds using the concept of mapping. The possible world in his account is a continuous mapping from the individuals to the space of properties. As in Kaczmarek's account the underlying "mathematical materials" were funtions. ${ }^{1}$

\section{B. An Outline of the Note}

The aim is to defend the theory of Ideas against traditional counterarguments. The starting point are the theories of Ideas of Plato and Ingarden and an ontology of Ideas proposed by Kaczmarek; these theories are paraphrased-using a modified method of semantic paraphrases of Ajdukiewicz-and presented in terms of the basic concepts of category theory. To paraphrase Ideas as categories I propose recognized category theory as a pattern for the theory of Ideas. I invoke an arrowslike, i.e. no-object-oriented, formulation of a category and I base the proposed theory of Ideas on that formulation. The components of an Idea are arrows and their compositions (equivalents of changes and transformations); objects in this approach are special arrows (identity arrows). One can understand the arrow as it appears in category theory as a generalized function-in this sense our approach is the generalization of the above-mentioned Kaczmarek and Mormann's study. Using the category of higher dimensions I introduce the concept of dimension of an Idea (and other concepts) which allows me to refute the argument of the "third man".

\section{Mathematical Philosophy}

A. Ajdukiewicz's Semantic Paraphrase of the Philosophical Issue as an Example of Qualitative Reasoning in Philosophy

In general we can say that the semantic paraphrase method is the method of translating traditional philosophical issues into the language of logic (or metalogic). The method consists of the following steps cf. (Woleński, 1989):

(i) the most accurate and clear identification of the philosophical issues under consideration;

(ii) selection of a logical theorem having a similar structure to that formulated problem of (i);

(iii) determination of certain compounds (of syntactic, semantic or pragmatic nature) between the expressions of (i) and the expressions of a logical theorem from (ii);

(iv) construction of a paraphrase, that is a sentence of a "isomorphic" structure with a selected logical theorem, i.e. an unambiguous assignment of meanings of expressions from (i) meanings of expressions from (ii);

(v) to validation of the paraphrase by

$\left(\mathrm{v}_{a}\right)$ phenomenological analysis,

$\left(\mathrm{v}_{b}\right)$ meaning postulates, i.e. assigning in an arbitrary manner some meaning to the expres-

${ }^{1}$ Needless to say that Mormann's account has nothing to do with Ideas. sions; by convention, or postulates or some definitions;

(vi) drawing consequences from the paraphrase;

(vii) evaluation of these consequences from the perspective of the philosophical problem under consideration.

Ajdukiewicz in A Semantical Version of the Problem of Transcendental Idealism (Ajdukiewicz, 1977, p. 140154) analysed the doctrine of transcendental idealism which amounts to the claim that "reality is a correlate of the transcedental subject" (see also (Przełęcki, 1990)). This thesis was translated into the claim that any statement of the language of science is true if and only if it is "dictated by the meaningrules of that language". In fact, from a metalogical point of view it is obvious that this position is not correct.

The core of Ajdukiewicz's method is the above-mentioned translation (or construction of a paraphrase) which must be preceded by an appropriate recognition of the problem.

\section{B. A Revised Version of Ajdukiewicz's Method}

Ajdukiewicz was a logic-centered philosopher. For this reason the second step (ii) of his method consists only of logical theorems. I am elaborating his method by extending its applicability to the entire field of mathematics — not only to logic or metalogic. ${ }^{2}$ Furthermore Ajdukiewicz believed that we would find similarities between theorems that are in fact between language expressions. I suggest we focus our attention on the analogy between the formal structures hidden behind the problem in question. It is not easy to say what these underlying formal structures are. ${ }^{3}$ Indeed the proper answer to this question requires the general metaphysical theory of formal structures. Mac Lane puts forward one of the possible theories of the origins and development of the structures in his Mathematics: Form and Function (Mac Lane, 1986). Mac Lane as a philosoper was anti-platonic, nevertheless his ideas can be used to explain the concept of the structure and the analogy between the structures even in our platonic approach.

\section{Basic Paraphrase: Ideas as Categories}

I suggest-thinking qualitatively - that the categories of category theory correspond to the Ideas. This correspondence is the (iv) step of the paraphrase method described above. The Ideas are composed of similar data as the categories and behave similarly to the categories. In other words, I suggest that category theory is a good approximation (a model? a material?) and description of the theory of Ideas.

In order to justify the paraphrase, to satisfy the $(\mathrm{v})$ condition from Ajdukiewicz's method, one should say the following: categories (in terms of category theory) are similar to Ideas (in terms of philosophy) in many respects; objects are incarnations of Ideas, fall within Ideas, participate in them, and-mimicking them—are modelled by them in metaphysics.

\footnotetext{
${ }^{2}$ An ontological analysis of the extension carried out using the topological tools can be found here (Skowron, 2014).

${ }^{3}$ In this sense Hilbert spaces in quantum mechanics are the underlying structures of the quantum world.
} 
Objects of mathematics, like groups, rings, fields, orders, proofs and so on, also fall within categories, in the sense of taking part in them, or are modelled by them ${ }^{4}$. Category theory is a theory of Ideas for mathematical objects. Not only mathematical objects are involved in categories. An application of category theory (and also all mathematics) in modern physics testifies to the fact that categories are in some way also present in the real world.

Ideas are the categories. Using the ontological analysis of Ideas carried out by Ingarden (Ingarden, 1925, 1965) one can say that a constant of the content of Ideas is based upon the fact that we are talking about this and not another category. A constant of the group category GRP will therefore be the fact that its objects are groups and its arrows are the group homomorphisms. The variable content of the category of groups GRP is the possibility of concretization of a variety of groups. The constant of the group category GRP is an ideal concretization of the possibility of concretization of some groups and their homomorphisms.

\section{The Metaphysical Result of Qualitative REASONING}

Philosophers such as Plato and Ingarden focused on describing the interior of Ideas. They believed that the essence of Ideas is hidden inside them. In fact, the opposite is the case. Ideas are byproducts of change. It is convenient to use the expression Idea, but the essence of Ideas is that they are secondary entities with respect to changes and transformations. That is why one should focus on the relationships between Ideas.

1) Why All This? The Newly Identified Features of Ideas:

On the basis of paraphrases one can identify the new features of Ideas:

1) the dynamical structure of Ideas (referring to the arrowsonly definition of a category (Mac Lane, 1998, p. 9));

2) the object of an Idea as the identity transformation within the Idea;

3 ) the dimension of Ideas (referring to the $n$-category theory (Baez, 1997));

4) the negations and oppositions of Ideas (referring to the concept of dual category $\mathbf{C}^{o p}$ );

5) the start and end of some Ideas (referring to the initial and terminal objects);

6) the full-fledged structural and, in fact, transcendental mereology of Ideas (referring to the proposal of updating mereology by a category theory done by Mormann (Mormann, 2009));

7) the tangled Ideas (on the basis of the adjoint functors (Mac Lane, 1998, p. 79-108));

8) the Idea of the Ideas (referring to the category of small categories);

9) the problem of the spatiality of Ideas (referring to the geometrical aspects of categories).

${ }^{4}$ It is worth mentioning that the Ideas in metaphysics can also fall within Ideas, not only within real objects. The Idea of man falls within the Idea of animal.

\section{A. Refutation of the Arguments Against the Theory of Ideas}

Using the identified properties of Ideas I can reject the following arguments:

- the Third Man Argument (by using the dimensions of Ideas)

- the Negation Argument (by using the opposite category)

- the One-Many Argument (by using the basic properties of the creation of a new category from an old one)

- the Pattern Argument (following the basic properties of $n$-dimensional Ideas)

\section{B. Ideas are Byproducts of Change}

The characteristics of a category introduces three types of entities: objects, arrows and compositions. Categories, however, were introduced in order to define the morphisms (and morphisms to define a natural transformation), namely to give them domain and counterdomain (Eilenberg and Mac Lane, 1945, p. 247). The concept of category was therefore an auxiliary concept. This is expressed in the fact that a category could be equivalently defined without the concept of object and using the concept of the arrow and composition (Mac Lane, 1998, p. 9)

On the basis of the paraphrase method, to be more specific by the condition number (vi), one can claim that an Idea is just a byproduct of transformations or a pure change. The realm of Ideas is not as stable and unchangeable as Plato imagined. In the face of the fact that a structure of the category TOP is not known in all its details, one can claim that these totalities of Ideas are complicated and there are no easy and obvious instruments to comprehend them. The ontological structure of the realm is a network of mutually influencing and co-creating Ideas.

\section{REFERENCES}

Ajdukiewicz, K. (1977). The Scientific World-Perspective and Other Essays, 1931-1963. Synthese Library. Springer.

Armstrong, D. (1989). A Combinatorial Theory of Possibility. Cambridge Studies in Philosophy. Cambridge University Press.

Awodey, S. (1996). Structure in Mathematics and Logic: A Categorical Perspective. Philosophia Mathematica, 4(3):209-237.

Awodey, S. (2014). Structuralism, Invariance, and Univalence. Philosophia Mathematica, 22(1):1-11.

Baez, J. C. (1997). An introduction to $n$-categories. In Moggi, E. and Rosolini, G., editors, Category Theory and Computer Science, volume 1290 of Lecture Notes in Computer Science, pages 1-33. Springer Berlin Heidelberg.

Beck, M. (1929). Ideelle Existenz. Philosophische Hefte, pages 151-239.

Bell, J. L. (2001). Observations on category theory. Axiomathes, 12(1-2):151155.

Eilenberg, S. and Mac Lane, S. (1945). General theory of natural equivalences. Trans. Am. Math. Soc., 58:231-294.

Fine, K. (1995). The logic of essence. Journal of Philosophical Logic, 24(3):241-273

Héring, J. (1921). Bemerkungen über das Wesen, die Wesenheit und die Idee. Jahrbuch fuür Philosophie und phänomenologische Forschung, pages 497 543.

Ingarden, R. (1925). Essentiale Fragen. ein Beitrag zu dem Wesensproblem. (eng. Essential Questions; pol. O pytaniach esencjalnych). Jahrbuch fuür Philosophie und phänomenologische Forschung, pages 125-304.

Ingarden, R. (1965). Der Streit um die Existenz der Welt (Eng. Controversy over the Existence of the World; Pol. Spór o istnienie świata). M. Niemeyer.

Kaczmarek, J. (2008). Indywidua. Idee. Pojecia. Badania z zakresu ontologi sfromalizawanej (Individuals. Ideas. Concepts. Research on formal ontology). Wydawnictwo Uniwersytetu Łódzkiego, Łódź. 
Lawvere, F. W. (1969). Adjointness in foundations. Dialectica, 23(3-4):281296.

Mac Lane, S. (1986). Mathematics: Form and Function. Springer-Verlag, New York, Berlin, Heidelberg, Tokyo.

Mac Lane, S. (1998). Categories for the Working Mathematician. Graduate Texts in Mathematics. Springer.

Mormann, T. (1997). Topological aspects of combinatorial possibility. Logic and Logical Philosophy, 5:75-92.

Mormann, T. (2009). Updating classical mereology. In Glymour, C., Westerstahl, D., and Wang, W., editors, Logic, Methodology and Philosophy of Science. Proceedings of the 13th International Congress. King's College. Plato (1997). Plato. Complete Works. Hackett Pub.

Przełęcki, M. (1990). Semantic reasons for ontological statements: The argumentation of a reist. In Woleński, J., editor, Kotarbinski: Logic, Semantics and Ontology, volume 40 of Nijhoff International Philosophy Series, pages 85-96. Springer Netherlands.
Simmons, H. (2011). An Introduction to Category Theory. Cambridge University Press.

Skowron, B. (2014). The Forms of Extension. In Szatkowski, M. and Rosiak, M., editors, Substantiality and Causality, pages 191-203. Walter de Gruyter, Berlin/New York.

Skyrms, B. (1993). Logical atoms and combinatorial possibility. Journal of Philosophy, 60(5):219-232.

Whitehead, A. (2010 (1929)). Process and Reality. Free Press.

Woleński, J. (1988). Logic and Philosophy in the Lvov-Warsaw School. Synthese Library. Springer Netherlands.

Woleński, J. (1989). Kierunki i metody filozofii analitycznej. In Perzanowski, J., editor, Jak filozofować, Studia z metodologii filozofii, pages 30-77. Polskie Wydawnictwo Naukowe.

Zalta, E. (1983). Abstract Objects: An Introduction to Axiomatic Metaphysics. Synthese Library. Springer. 